\title{
Promoting Youth Emergency Preparedness through Lifesaving Emergency Skill Workshops
}

\author{
Tanisha Martheswaran
}

\section{POSTER PRESENTATION ABSTRACT | PROGRAM DEVELOPMENT \& EVALUATION CATEGORY}

Introduction: Recognizing the growing emphasis on youth emergency preparedness, as seen through the increasingly common graduation requirement of CPR training and through skill training camps, members of Harvard CrimsonEMS expanded outreach to Greater Boston high-school students through the formation of the CrimsonEMS Youth Education Task Force. This novel task force seeks to create a more medically-literate youth community through fostering preparedness in basic lifesaving skills and placing an emphasis on bystander intervention.

Program Development \& Implementation: The task force, comprising of collegiate EMTs, designed a 90-minute workshop instructing students about taking proper action during common medical emergencies. This hands-on, rotating, station-based workshop covers CPR/ AED, Choking Management, EpiPen administration, and Bleeding Control. Stations have an average studentto-teacher ratio of 4:1, allowing for personalized instruction and feedback.

Program Evaluation: To date, the task force has reached over 170 high-school students from 9 workshops across Boston. Anonymous surveys were administered after workshop completion to assess the overall effectiveness of workshops based on confidence levels with basic medical skills on a five-point scale, with confidence defined as likelihood to utilize these skills during medical emergencies. With a $98 \%$ response rate from 170 students, $32 \%$ had previous firsthand exposure to at least one of the medical emergencies covered in the workshop. Prior to the workshop, students had an average skill confidence level of 2.96 out of 5; after workshop completion, skill confidence rose to 4.48 out of 5 , with a notable $60 \%$ increase in bleeding control.

Discussion/Conclusions: Due to the developing nature of the program, this research is a quality improvement initiative, and substantial conclusions cannot yet be drawn from limited data. Moving forward, the task force hopes to incorporate asthma, overdose, and first-aid education, as well as to implement after-school programs or camps. This initiative demonstrates the ability for collegiate EMS organizations to engage with local youth to promote safer, more knowledgable communities.

Author Affiliations: From CrimsonEMS \& Harvard University - both in Boston, MA, USA (T.M.).

Address for Correspondence: Tanisha Martheswaran | Email: tmartheswaran@ college.harvard.edu

Conflicts of Interest/Funding Sources: By the JCEMS Submission Declaration Form, all authors are required to disclose all potential conflicts of interest and funding sources. The authors declared that they have no conflicts of interest. The authors declared that they did not receive funding to conduct the program or research associated with this work.

Ethical Compliance: The authors attest that the research associated with this abstract was conducted in accordance with the JCEMS Ethics Guidelines.

Submission History: Received November 26, 2019; accepted for presentation and publication February 7, 2020.

Poster Presentation: This abstract was presented as a poster at the Academic Poster Session of the 27th Annual Conference of the National Collegiate Emergency
Medical Services Foundation; February 29, 2020; Boston, MA, USA.

Published Online: December 31, 2020

Published in Print: December 31, 2020 (Volume 3: Issue 2)

Reviewer Information: In accordance with JCEMS editorial policy, poster presentation abstracts undergo double-blind peer-review by at least two reviewers (JCEMS Editorial Board members and/or independent reviewers) prior to acceptance for presentation and publication. JCEMS thanks the anonymous reviewers who contributed to the review of this work.

Copyright: (c) 2020 Martheswaran. This is an open access article distributed under the terms of the Creative Commons Attribution 4.0 International (CC BY 4.0) License, which permits unrestricted use, distribution, and reproduction in any medium, provided the original author and source are credited. The full license is available at: https://creativecommons.org/licenses/by/4.0/

Electronic Link: https://doi.org/10.30542/JCEMS.2020.03.S1.06 